\title{
Predicting Annual Fecundity from Nest Success
}

\author{
T.M. Donovan ${ }^{1, *}$, C.M. Danforth ${ }^{2}$ and D.P. Shustack ${ }^{3}$
}

${ }^{1}$ United States Geological Survey, Vermont Cooperative Fish and Wildlife Research Unit, 311 Aiken Center, University of Vermont, Burlington, VT 05405; ${ }^{2}$ Department of Mathematics and Statistics, College of Engineering and Mathematical Sciences, University of Vermont, Burlington, VT 05401 and ${ }^{3}$ Rubenstein School of Environment and Natural Resources, University of Vermont, Burlington, VT 05405, USA

\begin{abstract}
Nest success, the probability that a nest will fledge offspring, is a widely measured parameter in ornithological studies, and is usually estimated by monitoring the fates of nests throughout a breeding season. Because nest success estimates are commonly reported in the avian literature, a key question in population studies is how to derive annual fecundity rates, $F$ (a vital parameter in population biology), from nest success data when breeding individuals are not marked. In this manuscript, we describe a simple, recursive model that generates an estimate of the frequency distribution of annual fecundity rates that can be achieved for a species, given precise and unbiased estimates of nest success, the average number of young that fledge per successful nest, and three life history parameters: the maximum number of possible successful broods per breeding season $(J)$, the maximum number of possible nesting attempts per breeding season $(K)$, and the maximum brood size $(B)$. We illustrate the model for 3 hypothetical species in which the average young that fledge per successful nest is 2 offspring: (1) a single-brooded species in which $J=1, K=3, B=3$; (2) a double-brooded species in which $J=2, K=3, B=3$, and (3) a triple-brooded species in which $J=3, K=3, B=3$.

In general, the frequency distributions of acceptable fecundity solutions for single-, double-, and triple-brooded species are all approximately symmetric, and are defined by $F_{\text {ave }}$ (the average acceptable solution), $F_{\text {min }}$ (the minimum acceptable solution), and $F_{\max }$ (the maximum acceptable solution). The "breadth" of these distributions, or the difference between $F_{\min }$ and $F_{\max }$, appears to be controlled largely by solutions where an unequal number of young fledge across attempts. However, when examining relationships between annual fecundity and nest success across the full spectrum of nest success values, we find that, more often than not, non-linear relationships characterized the association between nest success, $F_{\max }, F_{\min }$, and $F_{\text {ave }}$. The only case where nest success predicts annual fecundity in a linear fashion occurred when $J=K$. Thus, the assumption that nest success is an adequate indicator of annual fecundity should be viewed with caution.
\end{abstract}

\section{INTRODUCTION}

In many ornithological studies, nest success is defined as the probability that a nest will fledge offspring. Aside from distribution measures, nest success (often called nest survival) is one of the most widely reported metrics in articles describing breeding bird biology, and is typically measured by monitoring the fates of nests throughout a breeding season [1]. Methods for estimating nest success have gained much attention in recent decades. In 1961, Mayfield provided researchers with a method for estimating nest success in an unbiased fashion [2, 3]. Johnson [4] subsequently suggested an improved method, and Hensler and Nichols [5] and Bart and Robson [6] provided a means of calculating standard errors (see also Manolis et al. [7] and Rotella et al. [8] for discussions of standardizing data). Additionally, the computation of nest success has become straightforward with computer programs such as MAYFIELD [6], MARK $[9,10]$ and logistic exposure models in SAS [11].

*Address correspondence to this author at the United States Geological Survey, Vermont Cooperative Fish and Wildlife Research Unit, 311 Aiken Center, University of Vermont, Burlington, VT 05405, USA; Tel: 802-6562516; E-mail: tdonovan@uvm.edu
Today, researchers estimate nest success for a variety of reasons. Primary among these is to determine which habitats are deemed high in breeding quality from a conservation and management perspective [12]. Because density of birds may not always reveal which habitats are highest in quality [13], nest success has become the quality-indicator of choice (e.g., [14]). Additionally, nest success has been used to develop and test density dependence, habitat selection, and life history theory (e.g., [15-17]).

Nest success is an attractive metric for researchers because it can be measured without color- banding individuals, which can be enormously time and labor intensive. In studying the breeding biology of an unmarked population of birds, field workers simply search for nests at regularly defined intervals across the nesting season, and then monitor any encountered nests until the young fledge or until the nest fails. Thus, in the absence of color-banded individuals, observers collect information on the success or failure of individual nests and the number of young that fledge per successful nest, but lack information on whether the nest is a first, second, third, etc. attempt for a breeding female. In contrast, annual fecundity, $F$, is the total number of offspring fledged per female per breeding season, and is a function of 
the number of nest attempts made per female across the breeding season, the total number of successful broods raised in a single season, and the number of young that are fledged from a successful attempt [18-20]. In most cases, estimation of $F$ requires at least some portion of the breeding population be individually marked and subsequently monitored throughout the breeding season. Perhaps due to the "ease" of estimating nest success compared to annual fecundity, a recent review of 356 articles reporting productivity estimators found that $54 \%$ reported nest success rates, while only $10 \%$ reported annual fecundity rates [1].

Because nest success estimates are commonly reported in the avian literature, a key question is how to derive annual fecundity rates, $F$ (a vital parameter in population biology), from an estimate of nest success when birds are not individually marked. Pease and Grzybowski [20] developed a model to estimate annual fecundity rates in passerines. Their model is a bookkeeping approach, which tracks the fates of all breeders through time and requires estimates of dates of susceptibility of parasitism and predation, probabilities of abandonment, and timing of nest building and nest termination. This is an excellent approach if nest success is constant through the breeding season and if one has the data needed to parameterize it; however, in many cases investigators do not have the critical pieces of information needed and a more simplistic approach is needed.

In this manuscript, we describe a simple, recursive model that provides the distribution of possible annual fecundity rates that can be achieved for a species, given precise and unbiased estimates of nest success for the breeding population $(\hat{S})$ and the average number of young fledged per successful nest attempt $(\hat{y})$, plus three life history parameters: the maximum number of possible successful broods per breeding season $(J)$, the maximum number of possible nesting attempts per breeding season $(K)$, and the maximum brood size per nest $(B)$. In comparison to the Pease and Gryzbowski [20] model, our model is not based on calendar date. Rather, it takes an inverse approach, finding all annual fecundity rates that are possible for a species whose breeding life history is defined by $J, K$, and $B$, under the constraint that the season long nesting success and average number of young fledged per successful nest values calculated from the model match the empirically derived estimates, $\hat{S}$ and $\hat{y}$. We illustrate the model for 3 hypothetical species: (1) a singlebrooded species in which $J=1, K=3, B=3, \hat{y}=2$; (2) a double-brooded species in which $J=2, K=3, B=3, \hat{y}=2$, and (3) a triple-brooded species in which $J=3, K=3, B=3, \hat{y}=2$. We then discuss the general applicability of the model for population studies.

\section{THE MODEL}

All letters and symbols used in this paper are defined in Appendix 1. The model was programmed in MATLAB and consists of a recursion formula describing how the total number of attempts in iterate $i$ relates to the total number of attempts in iterate $i$-1 (Appendix 2). Inputs include $N$ (the number of breeding females), $J$ (the maximum number of total broods that can be produced per breeding season), $K$ (the maximum number of total nest attempts that can be made per breeding season), $B$ (the maximum possible brood size), $\hat{S}$ (a robust estimate of season-long nest success), and $\hat{y}$ (a robust estimate of the season-long average number of young fledged per successful nest attempt). With the assumption that no individuals are marked, $\hat{S}$ and $\hat{y}$ are estimated by monitoring nests throughout the breeding season (denoted by the carat), while $J, K$, and $B$ are estimated based on the literature and expert knowledge of the species. Note that $B$ can also be estimated by monitoring nests of unmarked individuals. $N$ is arbitrary but could be estimated with a variety of different methodologies [21]. The key model output is a frequency distribution that provides the mean $\left(F_{\text {ave }}\right)$, minimum $\left(F_{\text {min }}\right)$ and maximum $\left(F_{\max }\right)$ annual fecundity rates that can be achieved, given $\hat{S}, \hat{y}, J, K, B$.

The model tracks the fates of nesting attempts for all breeding individuals across the entire breeding season, in which the outcome of each nest attempt is either success or failure, and includes stopping decisions such that total broods cannot exceed $J$ and total attempts cannot exceed $K$ for any given female.

For a species with $K$ possible total nesting attempts per year, let $t_{i}$ represent the total number of $i$ th nesting attempts made by the entire population for $i=1,2,3, \ldots, K$. Let $p_{i}$ be the probability that a nest will succeed in attempt $i$, and $y_{i}$ be the number of young that fledge per successful nest in attempt $i$. Thus, $\left(1-p_{i}\right)$ is the probability that a nest will fail in attempt $i$.

With two possible outcomes per attempt $i$ (success or failure), and $K$ total attempts, the number of nest attempts can be viewed as a decision tree, in which the root of the tree represents the first breeding attempt $(i=1)$, and each node represents success or failure of a nest attempt (Fig. 1). The full tree is represented by $K$ rows, where a row represents attempt $i . T_{i, m}$ gives the total number of nesting attempts for a given leaf in the tree, identified by the subscripts $i$ (attempt) and $m$ (the position of the leaf in a given row); $t_{i}$ represent the total number nesting attempts across a row. For all $i \geq 2$, when $m$ is odd, the previous nest attempt failed, and when $m$ is even, the previous nest attempt succeeded. The number of unique paths from the root of the tree to the branch tips is $2^{K-1}$.

To ensure that females cannot exceed $K$ attempts, we introduce the placeholder $a_{i}$ to identify the attempt number, where $a_{i}=1$ for $i \in\{1,2,3, \ldots, K\}$ and $a_{i}=0$ for $i \in\{K+1, K+$ $2, K+3, \ldots\}$. To ensure that females cannot exceed $J$ broods, we introduce the placeholder $b_{j}$ to track the total number of previously successful broods, where $b_{j}=1$ for $j \in\{0,1,2,3, \ldots$, $J-1\}$ and $b_{j}=0$ for $j \in\{J, J+1, J+2, J+3, \ldots\}$. Thus, $a_{i}$ and $b_{j}$ are binary and act as "switches" that control whether the nest attempts in leaf $T_{i, m}$ contribute to $t_{i}$.

The model can be conceptualized as follows. Nesting attempt $i=1$ (row 1, Fig. 1) defines the total number of first nesting attempts made by the breeding population: $T_{1,1}=$ 


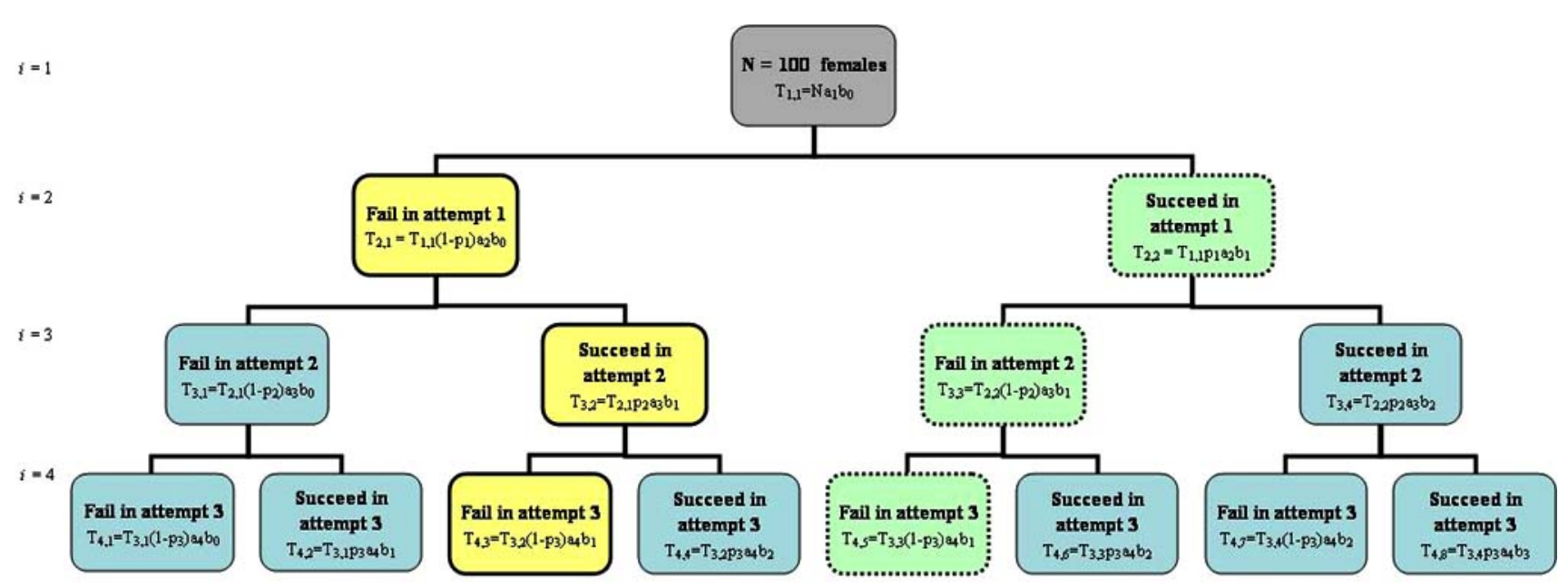

Fig. (1). An example of a tree depicting total number of nest attempts, $T_{i, m}$ at each leaf for four iterations. Thus, $K=4$ and the number of unique branching paths is $2^{4-I}=8$. The outcome of the fourth attempt is not shown but is included in the model. Two unique branching paths are shown (yellow and green, which share the first attempt, $K=1$, shaded gray). The paths illustrate how the total number of attempts in iterate $i$ relates to the total number of attempts in iterate $i-1$.

$N a_{1} b_{0}$, where $a_{l}=1$ and the subscript indicates attempt number 1 , and where $b_{0}=1$ and the subscript 0 indicates that, in this first iteration, no females have successfully fledged a brood. In iteration $2(i=2$, row 2 , Fig. 1), the total number of second nest attempts is the total number of females whose first attempt failed and initiated a new attempt [leaf $T_{2,1}=$ $\left.T_{1,1}\left(1-p_{1}\right) a_{2} b_{0}\right]$, plus the total number of females whose first attempt succeeded and are attempting a second brood [leaf $\left.T_{2,2}=T_{1,1} p_{1} a_{2} b_{1}\right]$. In iteration 3 ( $i=3$, row 3, Fig. 1), the total number of third nest attempts is the total number of females whose first and second nest attempts failed $\left[T_{3,1}=T_{2, I}(1\right.$ $\left.\left.p_{2}\right) a_{3} b_{0}\right]$, plus the total number of females whose first attempt failed but second nest succeeded $\left[T_{3,2}=T_{2,1} p_{2} a_{3} b_{1}\right]$, plus the total number of females whose first attempt succeeded but second nest failed $\left[T_{3,3}=T_{2,2}\left(1-p_{2}\right) a_{3} b_{1}\right]$, plus the total number of females whose first and second attempts succeeded $\left[T_{3,4}=T_{2,2} p_{2} a_{3} b_{2}\right]$. When $a_{i}>K$, or when $b_{\mathrm{j}} \geq J, T_{i, m}=0$ and the leaf does not contribute to the total nest attempts for any given $i$.

The decision tree can be described mathematically with the recursion below to build a general model for a species with $J$ broods and $K$ nest attempts in a season. Assuming that all females make a first nesting attempt,

$$
\mathrm{T}_{1,1}=\mathrm{Na}_{1} \mathrm{~b}_{0}
$$

which establishes the initial condition for the recursive model. Then, for all attempts $i=2,3 \ldots, K$ and $m=1,2,3$, $\ldots .2^{i-1}$, the total number of nest attempts made by the breeding population for any leaf in the tree is given by the recursive equation:

$$
T_{i, m}=\left\{\begin{array}{lc}
T_{i-1,}\left[\frac{m}{2}\right]^{\left(1-p_{i-1}\right) a_{i} b_{\alpha(i, m)}} & \text { if } m \text { is odd } \\
T_{i-1,1}\left\lceil\left.\frac{m}{2}\right|^{p_{i-1}} a_{i} b_{\alpha(i, m)}\right. & \text { if } m \text { is even }
\end{array}\right.
$$

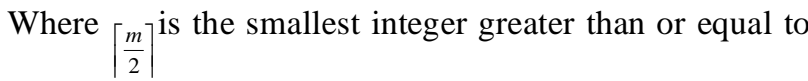
$m / 2$, otherwise known as the ceiling of $m / 2$, and $\alpha(i, m)$ is given by the following recursion: $\alpha(1,1)=0$. Then for $i=2$, $3,4, \ldots, K$ and $m=1,2,3, \ldots, 2^{i-2}$;

$$
\begin{aligned}
& \alpha(i, m)=\alpha(i-1, m) \\
& \alpha\left(i, m+2^{i-2}\right)=\alpha(i-1, m)+1
\end{aligned}
$$

The total attempts at iterate $i$ is given by the sum

$$
t_{i}=\sum_{m=1}^{2^{i-1}} T_{i, m}
$$

Nest success from the model $\left(S^{*}\right)$ is then computed as

$$
S^{*}=\frac{\sum_{i=1}^{K} t_{i} p_{i}}{\sum_{i=1}^{K} t_{i}}
$$

Annual fecundity from the model $\left(F^{*}\right)$ is computed as

$$
F^{*}=\frac{\sum_{i=1}^{K} t_{i} p_{i} y_{i}}{N}
$$

and the season-long average young produced per successful nest from the model is computed as

$$
\bar{y} *=\frac{\sum_{i=1}^{K} y_{i}}{\sum_{i=1}^{K} t_{i} p_{i}}
$$


In the recursive model, the $p_{i}$ 's (the probability that a nest in attempt $i$ will succeed) are completely unknown, and can range between 0 and 1 . The $y_{i}$ 's (the number of young that fledge per successful nest in attempt $i$ ) are also unknown, with the constraint $0<y_{i} \leq B$, where $B$ is the maximum brood size for a given species. For the given model inputs $N$, $J$, and $K$, the distribution of possible annual fecundity rates is estimated by allowing the $p_{i}^{\text {'s }}$ to vary between 0 and 1 by increments of 0.01 (with varying combinations of the $p_{i}$ 's referred to as a trial or scenario), and by simultaneously allowing the $y_{i}$ 's to vary between $0<y_{i} \leq B$ in increments of 0.5 (or smaller). After running all possible combinations, the solutions for those trials where $S^{*}=\hat{S}$ and where $\bar{y} *=\hat{y}$ are retained. All trials satisfying this relationship are then used to compute the distribution of possible annual fecundity rates.

We illustrate the model for three hypothetical species. The first hypothetical species is a single-brooded species in which $J=1, K=3, B=3$, and $\hat{y}=2$. Thus, the decision tree in Fig. (1) would be reduced by one row. For this hypothetical species, the average number of young that fledge per successful nest is 2 offspring ( $\hat{y}=2)$, which is estimated from hypothetical field efforts, and the maximum brood size is 3 . Females that are successful in their first attempt do not initiate new attempts, whereas females that fail their first attempt will initiate a second attempt. Those that are successful do not initiate a third attempt, while those that fail in the first and second attempts will initiate a third attempt. The second hypothetical species is a double-brooded species in which $J$ $=2, K=3, \mathrm{~B}=3$, and $\hat{y}=2$. As with species 1 , breeding females of hypothetical species 2 can have a maximum of 3 nesting attempts per year and a maximum brood size of 3 , but females that successfully fledge a brood in either attempt 1 or attempt 2 will initiate a new nest attempt in an effort to produce a second brood. After the second brood is successfully fledged, females do not make any additional nest attempts. The third hypothetical species is a triple-brooded species in which $J=3, K=3, \mathrm{~B}=3$, and $\hat{y}=2$. Thus, all individuals in the population make three attempts, regardless of whether the nests fail or succeed.

\section{MODELING OBJECTIVES}

For each hypothetical species, our objectives were to: (1) Illustrate the model by generating a frequency distribution of possible annual fecundity rates for a hypothetical, specific case where $\hat{S}=0.4$ and $\hat{y}=2$. Only those model solutions where $S^{*}=\hat{S}=0.4$ and where $\bar{y} *=\hat{y}=2$ are used in constructing the distribution of possible annual fecundity rates; (2) Examine a specific subset of solutions from objective 1, including (a) $S^{*}=\hat{S}=0.4 ; y_{1}=y_{2}=y_{3}=2$ (2 young fledged per successful nest, regardless of attempt number, $\bar{y} *=\hat{y}=2$ ), (b) $S^{*}=\hat{S}=0.4 ; y_{1}=3, y_{2}=2, y_{1}=1$ (decreasing number of young fledged per successful attempt, $\bar{y} *=\hat{y}=2$ ), and (c) $S^{*}=\hat{S}=0.4 ; y_{1}=1, y_{2}=2$, and $y_{3}=3$ (increasing number of young fledged per successful attempt, $\bar{y} *=\hat{y}=2)$. These specific scenarios were selected in an attempt to understand factors that influence the shape of the frequency distribution of acceptable solutions from objective 1 (the range of possible annual fecundity rates); (3) Repeat objective 2 for all levels of nest success (i.e. $S$ anywhere from 0 to 1 ) where $\hat{y}=2$ in an attempt to identify the general conditions in which annual fecundity is associated with nesting success, as well as the general conditions where annual fecundity and nesting success are unrelated.

\section{RESULTS}

In general, the frequency distributions of acceptable solutions, namely $S^{*}=\hat{S}$ and $\bar{y}^{*}=\hat{y}$, for single-, double-, and triple-brooded species are all approximately symmetric around $F_{\text {ave }}$. The "breadth" of these distributions (the difference between $F_{\max }$ and $F_{\min }$ ) appears to be controlled largely by solutions where an unequal number of young fledge across attempts. However, when examining a full range of nest success estimates, relationships between nest success, $F_{\max }, F_{\min }$, and $F_{\text {ave }}$ could be linear or non-linear, depending on $J$ and whether the number of young fledged per successful nest was constant across nest attempts or not. The only case where nest success predicts annual fecundity in a linear fashion occurred when $J=K$. Thus, the assumption that nest success is an adequate indicator of annual fecundity should be viewed with caution.

SINGLE-BROODED SPECIES, $J=1, K=3, B=$ 3, $\bar{y}=2$.

The model was run by letting $p_{i}$ vary between 0 and 1 in increments of 0.01 and by letting $y_{i}$ vary between 0 and $B$ in increments of 0.5 , and retaining only those solutions where $S^{*}=\hat{S}=0.4$ and $\bar{y}^{*}=\hat{y}=2$. A total of 1018830 trials (scenarios) were run for the single-brooded species, of which 17544 met the assumption that $S^{*}=\hat{S}=0.4$ and $y^{*}=\hat{y}=2$ and were retained and graphed. For the single-brooded species, acceptable solutions suggest that annual fecundity could range between $=0.3\left(F_{\min }\right)$ and $\sim 2.5\left(F_{\max }\right)$ offspring per breeding female, but the most frequent acceptable solution was $F_{\text {ave }}=$ 1.8 offspring (Fig. 2a).

To understand how different, acceptable model scenarios influence the shape of the frequency distribution in Fig. (2a), we graphed the results for a single-brooded species where $S^{*}=\hat{S}=0.4$ and $y_{i}{ }^{*}=\hat{y}_{i}=2$ but restricted our graphical analysis to three specific $y_{i}$ scenarios: (a) $S^{*}=\hat{S}=0.4$ and $y_{l}$ $=y_{2}=y_{3}=2$ ( 2 young fledged per successful nest, regardless of attempt number; $\bar{y} *=\hat{y}=2$ ), (b) $S^{*}=\hat{S}=0.4$ and $y_{l}=3$, $y_{2}=2, y_{1}=1$ (decreasing number of young fledged per successful attempt, $\bar{y} *=\hat{y}=2$ ), and (c) $S^{*}=\hat{S}=0.4$ and $y_{1}=1$, $y_{2}=2$, and $y_{3}=3$ (increasing number of young fledged per successful attempt, $\bar{y} *=\hat{y}=2$; Fig. 3a).

For a single brooded species, the majority of acceptable model solutions resulted in annual fecundity rates between 1.3 and 2 offspring per year when the $y_{i}$ 's were constant 

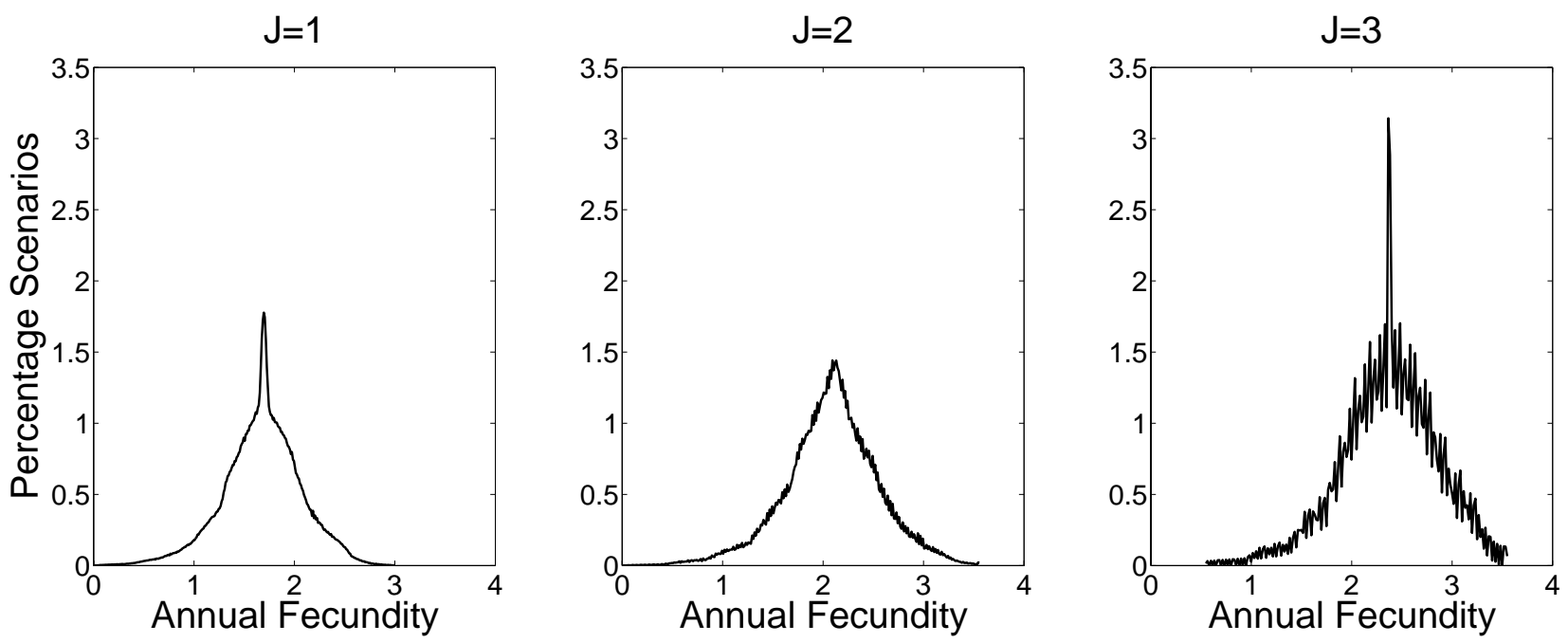

Fig. (2). Percentage of model scenarios and corresponding annual fecundity rates that met the assumption $S^{*}=\hat{S}=0.4$ and $\bar{y}^{*}=\hat{y}=2$ for single brooded species $(J=1)$, double-brooded species $(J=2)$, and triple brooded species $(J=3)$. For each species, the solution where fecundity is minimized is $F_{\min }$, the solution where fecundity is maximized is $F_{\max }$, and the average solution is $F_{a v e}$.
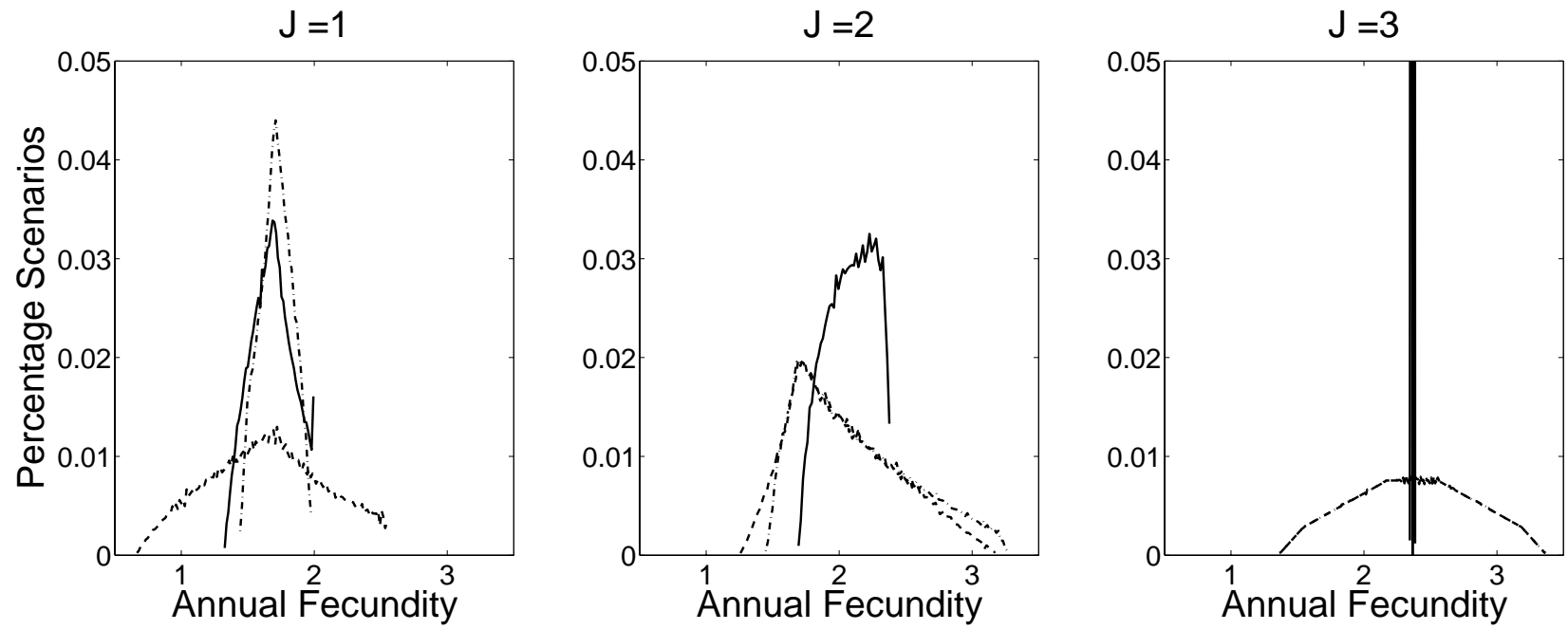

Fig. (3). Percentage of model scenarios and corresponding annual fecundity rates that met the assumption $S^{*}=\hat{S}=0.4$ and $\bar{y}^{*}=\hat{y}=2$ for single brooded species $(J=1)$, double-brooded species $(J=2)$, and triple brooded species $(J=3)$. Solid line $=$ solutions where $S^{*}=\hat{S}^{*}=0.4$; $y_{1}=y_{2}=y_{3}=2$. Dash-dot $=$ solutions where $S^{*}=\hat{S}=0.4 ; y_{1}=3, y_{2}=2, y_{1}=1$. Dashed line = solutions where $S^{*}=\hat{S}=0.4 ; y_{1}=1, y_{2}=2$, and $y_{3}=3$.

(Fig. 3a; solid line) or when the $y_{i}$ 's decreased with attempt number (Fig. 3a; dash-dot line), with the majority of acceptable solutions indicating annual fecundity is approximately 1.75. In contrast, when the $y_{i}$ 's increase with attempt number (Fig. 3a; dashed line), annual fecundity ranged between 0.5 and 2.5 offspring. Thus, model scenarios where $y_{i}$ 's increase with attempt number increased the range between $F_{\text {min }}$ and $F_{\max }$ in Fig. (1a), but did not change $F_{\text {ave }}$.

To identify the general conditions in which annual fecundity is associated with nesting success, and the general conditions where annual fecundity and nesting success are unrelated, we graphed $F_{\min }, F_{\max }$, and $F_{\text {ave }}$ for all nest success values for a single brooded species in which $K=3, B=3$, and $\hat{y}=2$. When $y_{1}=y_{2}=y_{3}=2$, the relationship between nest success and average annual fecundity rate, $F_{\text {ave }}$, was on asymptotic (Fig. 4a; solid line) with an inflection point at a season-long estimates of nest success $\sim 0.40$. Due to the asymptotic nature, nest success values from $\sim 0.5$ to 1 yielded nearly identical estimates of annual fecundity. Below the asymptote, nest success levels of $\sim 0.35$ had the greatest range in possible annual fecundity rates. For example, when nest success was 0.35 and $y_{1}=y_{2}=y_{3}=2, F_{\max }$ was 2.0 and $F_{\min }$ was 1.25 , yielding a difference of 0.75 offspring per breeding female between the maximum and minimum rates (Fig. 4a).

When the number of young fledged per attempt increased over the season $\left(y_{1}=1, y_{2}=2, y_{3}=3\right)$, the maximum per annual fecundity rate $\left(F_{\max }\right)$ was 3 and occurred at nest suc- 

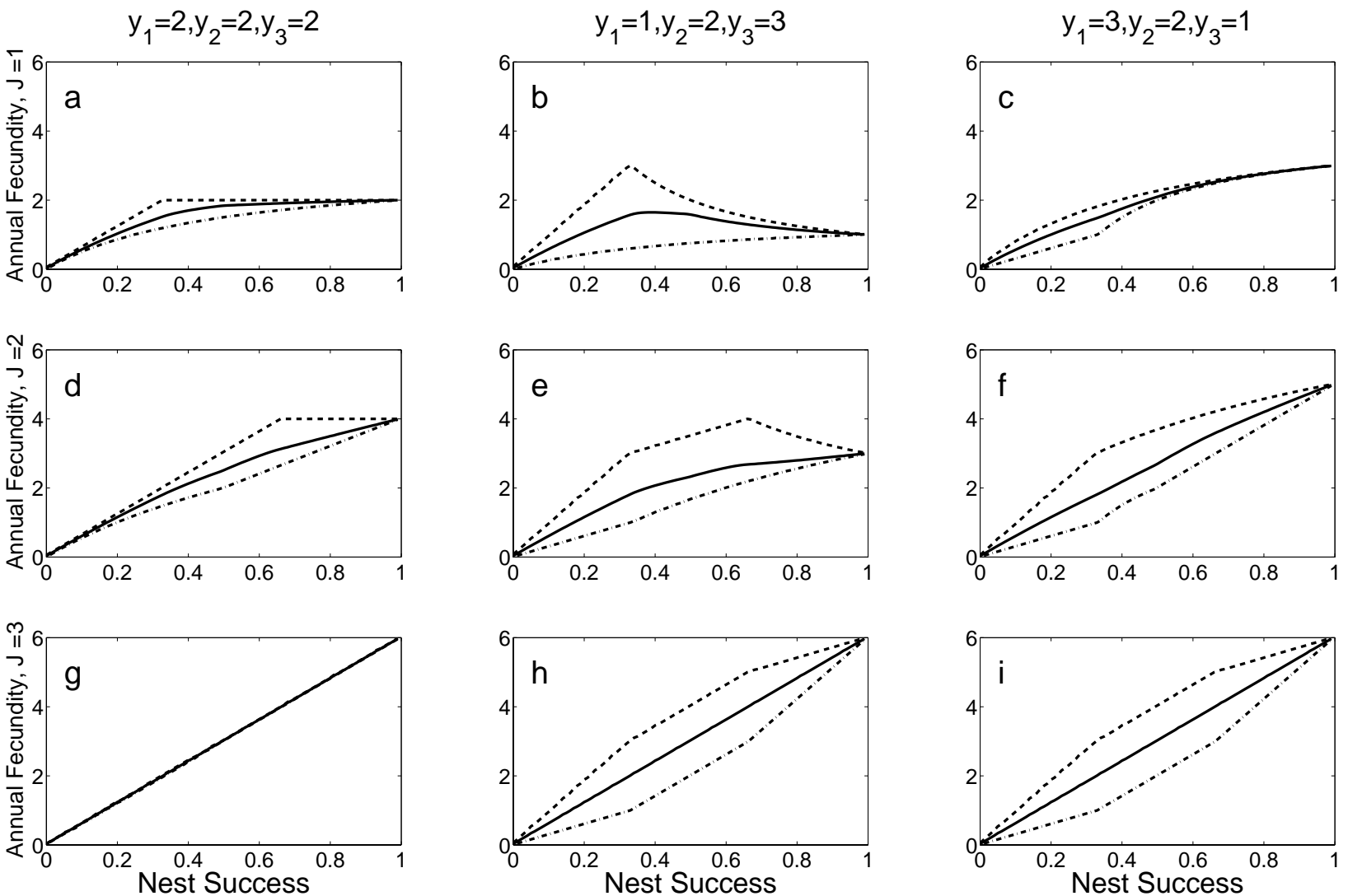

Fig. (4). Relationship between nest success and annual fecundity estimates for a single-brooded species $(J=1)$, double-brooded species $(J$ $=2$ ), and triple-brooded species $(J=3)$. All possible solutions that met the constraint that $\bar{y}^{*}=\hat{y}=2$ are shown, including $F_{\text {max }}\left(\right.$ dash), $F_{\text {min }}$ (dash-dot), and $F_{\text {ave }}$ (solid line).

cess levels $=0.35$ (Fig. $\mathbf{4 b}$; dashed line). However, this same nest success level could also result in $F_{\min }=0.62$ offspring per year (Fig. 4b; dashed-dot line), a difference of 2.38 offspring per year. Indeed, when the $y_{i}$ 's increased across attempts, there was a wide range of possible annual fecundity rates for most levels of nest success $<0.8$, suggesting that nest success is not a good indicator of annual fecundity under these conditions. In sharp contrast, when the number fledged per nest decreased with nesting attempts $\left(y_{1}=3, y_{2}=\right.$ $\left.2, y_{3}=1\right)$, measures of season-long nesting success were generally associated with average annual fecundity rates (Fig. 4c), though the relationship was asymptotic and the range in possible annual fecundity rates was considerable for nest success levels $<0.5$.

DOUBLE-BROODED SPECIES, $J=2, K=3, B=$ 3, $\bar{y}=2$.

The model was run by letting $p_{i}$ vary between 0 and 1 in increments of 0.01 and by letting $y_{i}$ vary between 0 and $B$ in increments of 0.5 , and retaining only those solutions where $S^{*}=\hat{S}=0.4$ and $\bar{y}^{*}=\hat{y}=2$. A total of 1010119 trials (scenarios) were run for the double-brooded species, of which 19008 met the assumption that $S^{*}=\hat{S}=0.4$ and $y^{*}=\hat{y}=2$ and were retained and graphed. For the double-brooded species, acceptable solutions suggest that annual fecundity could range between $=0.5\left(F_{\min }\right)$ and $3.5\left(F_{\max }\right)$ offspring per breeding female, but the most frequent acceptable solution was $F_{\text {ave }}=2.1$ offspring (Fig. 2b).

In contrast to the single-brooded species, the breadth of the frequency distribution in Fig. (2b) was strongly influenced by whether the $y_{i}$ were constant across attempts or not. In other words, there was a great range of possible annual fecundity rates in double-brooded species for cases where $y_{1}$ $=1, y_{2}=2, y_{3}=3$ (Fig. 3b; dashed line) or $y_{1}=3, y_{2}=2, y_{3}=$ 1 (Fig. 3b; dash-dot line) compared cases where $y_{i}$ are constant (Fig. 3b; solid line). The peaks of the distributions in Fig. (3b) indicated that the majority of trials resulted in an annual fecundity rate of $\sim 2.3$ for cases where the $y_{i}$ 's were constant over attempts, but only $\sim 1.6$ for cases where the $y_{i}$ varied with attempt.

To identify the general conditions in which annual fecundity is associated with nesting success for a doublebrooded species, we graphed $F_{\min }, F_{\max }$, and $F_{\text {ave }}$ for all nest success values for a double-brooded species in which $K=3$, $B=3$, and $\hat{y}=2$. The relationships between season-long nest success and annual fecundity for the double-brooded case were generally similar to the single-brooded case (Fig. 4 d, e, f), with some notable observations. First, as can be ex- 
pected, for any level of nest success, the range in annual fecundity rates possible for any given level of nest success is much greater compared to single-brooded species. Second, ranges of possible annual fecundity $\left(F_{\max }-F_{\text {min }}\right)$ were generally small at either low $(<0.15)$ or high $(>0.8)$ levels of season-long nest success, but could be quite large at intermediate levels of nesting success. Third, when the number fledged per attempt was not constant over attempt $\left(y_{1}=1, y_{2}\right.$ $=2, y_{3}=3$ or $\left.y_{1}=3, y_{2}=2, y_{3}=1\right)$, the range in possible annual fecundity rates for a given level of nest success was greater compared to cases where number fledged per attempt was constant.

TRIPLE-BROODED SPECIES, $J=3, K=3, B=$ $3, \bar{y}=2$.

The model was run by letting $p_{i}$ vary between 0 and 1 in increments of 0.01 and by letting $y_{i}$ vary between 0 and $B$ in increments of 0.5 , and retaining only those solutions where $S^{*}=\hat{S}=0.4$ and $\bar{y}^{*}=\hat{y}=2$. A total of 732201 trials (scenarios) were run for the triple-brooded species, of which 13353 met the assumption that $S^{*}=\hat{S}=0.4$ and $y^{*}=\hat{y}=2$ and were retained and graphed. For the triple-brooded species, acceptable solutions suggest that annual fecundity could range between $=0.5\left(F_{\min }\right)$ and $3.5\left(F_{\max }\right)$ offspring per breeding female, but the most frequent acceptable solution was $F_{\text {ave }}=$ 2.1 offspring (Fig. 2c).

The "spread" of Fig. (2c) is due exclusively to those trials where $y_{i}$ 's are variable in contrast to the case where $y_{i}$ 's are constant, in which all trials resulted in the same predicted annual fecundity rate of 2.3 (Fig. 3c).

The relationships between season-long nest success and annual fecundity for the triple-brooded case were generally similar to the double-brooded case (Fig. 4d, e, f), with some notable differences. First, although the range of possible fecundity rates was still quite large in cases where the $y_{i}$ are not constant with attempt, the asymptotic nature of the average trial result disappears and becomes more linear, such that the average of the model outputs is nearly the same across all cases. Second, in the case where $J=K$, there is a linear relationship between nest success and annual fecundity, and $F_{\text {ave }}$ $=F_{\text {min }}=F_{\text {max }}$.

\section{DISCUSSION}

Our modeling approach was designed with the assumption that researchers have no knowledge of whether a given nest represents the $1^{\text {st }}, 2^{\text {nd }}$, etc. nesting attempt, with the hope that the model outputs may be useful for conservation studies that require comparisons among different habitats across large geographic extents, or for studies that require relatively "quick" assessments of breeding habitat quality. Being attempt based does not imply that nests must synchronously fail or succeed and that all attempts $i$ are initiated in the same temporal period, although this may be the case. For example, suppose three nests were located on the same day, where nest 1 was the first attempt for female 1 , nest 2 was the second attempt for female 2, and nest 3 was the third attempt for female 3 . With an attempt-based modeling approach, the first nest contributes to $p_{1}$, the second nest contributes to $p_{2}$, and the third nest contributes to $p_{3}$, even if all three nests fail on the same day. Alternatively, if all nests happened to be the first attempt for all three females, all three nests would contribute to $p_{l}$. If birds are unmarked, a field researcher has no information about which of these two scenarios is true, and must consider both options. The model accommodates this uncertainty by letting the $p_{i}$ 's vary between 0 and 1 , under the constraint that only those model solutions where nest success from the model matches the empirically derived estimate of nest success, $S^{*}=S$, are retained. This approach is conservative because all $p_{i}$ 's between 0 and 1 are evaluated. However, the range of $p_{i}$ 's could be reduced (e.g., $0.2<p_{i}<$ $0.8)$ to obtain a better range of $F^{*}$ if biologists have a plausible idea of what the true range of $p_{i}$ 's could be.

In a recent review, Thompson et al. [1] showed that the avian literature poorly distinguishes between nesting success and annual reproductive success, and that most researchers do not account for renesting or multiple-brooding when they interpret nest success levels. Our results illustrate that specific annual fecundity rates can be produced by many different levels of season-long nest success, and conversely, that a specific level of season-long nest success can produce a wide range of possible annual fecundity rates. For instance, the range between minimum and maximum fecundity rates for single- or double-brooded cases was greatest when nest success was between 0.30 and 0.55 -commonly measured estimates of nest success $[1,22]$. In other words, the use of nest success as an indicator of fecundity rates is the least accurate for the most common empirical estimates of nest success. This result can be problematic for researchers who are interested in using nest success levels to assess population trajectories, source-sink status (e.g., [23]), or in tests of life-history theory, all of which require estimates of fecundity rates for a population.

Under what conditions, then, would investigators have "more faith" that their nest success estimates are relatively reflective of annual fecundity rates? Our results suggest that nesting success of multi-brooded species with relatively constant numbers of young fledging per successful nest over the breeding season is a reasonable measure of annual fecundity, especially when nest success levels are $<0.5$. However, when the number of young fledged per successful nest varies with attempt, the model indicates that any one level of nesting success can yield several different annual fecundity estimates. For instance, at nest success values of 0.4 for a double or triple brooded species, annual fecundity can range from < 1 to roughly 4 offspring per year. This is a tremendous difference in reproductive output from a population viability perspective.

We advocate caution in assuming that the number of young fledged per successful nest is constant across attempts because the ornithological literature suggests that this may not be the case. For example, Lowther [24] noted that an increasing number of offspring that fledge with later nesting attempts is commonly reported among passerines that experience brood reduction early in the season due to cowbird parasitism. Additionally, decreasing number of offspring that 
fledge with later nesting attempts can result from decreased clutch size or increased partial predation later in the season [25-27]. Thus, researchers are encouraged to report $F_{\max }$, $F_{m i n}$, and $F_{a v e}$ when applying the model to their field data.

In summary, significant analytic developments have been made in recent decades to estimate nest success in a precise an unbiased fashion. Given these approaches, our model provides researchers with ancillary information about the range of possible annual fecundity rates that are associated with a given nest success estimate. This information could be useful in conservation, management, and theoretical applications. The model code is posted at http://www.uvm.edu/ envnr/vtcfwru/spreadsheets/demographics/nestsuccess.htm.

\section{ACKNOWLEDGMENTS}

This manuscript greatly benefited from comments by Laura Nagy, Rollie Lamberson, Kerri Cornell, Adam Duerr, Melanie Driscoll Robert Long, Noah Perlut, Jim Nichols, Jim Hines, Craig Pease, and an anonymous reviewer. Our work on nest success and population viability is supported by NSF (0108875).

\section{Appendix 1. List of symbols used in model.}

$a_{i}=$ model placeholder to identify the attempt

$b_{j}=$ model placehold to track the total number of previously successful broods

$B=$ the maximum possible brood size

$\mathrm{F}^{*}=$ annual fecundity from the model

$F_{\text {ave }}=$ mean of the frequency distribution of all acceptable model solutions of $F^{*}$

$F_{\min }=$ minimum $\mathrm{F}$ of all acceptable model solutions of $F^{*}$

$F_{\max }=\operatorname{maximum} \mathrm{F}$ for all acceptable model solutions of $F^{*}$

$\mathrm{i}=$ subscript tracking the nesting attempt number in the model ( $\mathrm{i}=1$ to $K$ ).

$J=$ empirical estimate of the maximum number of total broods that can be produced per breeding season

$K=$ empirical estimate the maximum number of total nest attempts that can be made per breeding season;

$N=$ empirical estimate the number of breeding females)

$p_{i}=$ the probability that a nest will succeed in attempt $i$. The $p_{i}$ are unknown and are allowed to vary between 0 and 1 .

$\hat{S}=$ empirically derived estimate of season-long nest success

$\mathrm{S}^{*}=$ nest success from the model

$t_{i}=$ the total number of $i$ th nesting attempts made by the entire population for attempt $i=1,2,3, \ldots, K$.

$T_{i, m}=$ the total number of nesting attempts for a given leaf in the decision tree, identified by the subscripts $i$ (attempt) and $m$ (the position of the leaf in a given row) $\hat{y}=$ empirically derived estimate of the season-long average number of young fledged per successful nest attempt

$y_{i}=$ the number of young that fledge per successful nest in attempt $i$. The $y_{i}$ are unknown and allowed to vary between 0 and $B$ in small increments.

$\hat{y}^{*}=$ the season-long average young produced per successful nest from the model

\section{Appendix 2.}

function $[\mathrm{ns}, \mathrm{br}]=$ nest_function $(\mathrm{p}, \mathrm{y}, \mathrm{J})$

$\% \%$ Chris Danforth

$\% \% 8 / 10 / 07$

$\% \%$ This function takes as input the $\mathrm{K}$-dimensional vector $\mathrm{p}$ giving the probabilities of fledging young on the first, second, ... Kth breeding attempt. The outputs are the season long nest success ns and the per capita birth rate br. The main program above nest_function.m increments each component of $\mathrm{p}$ to generate a map of the possible outputs of nest_function. Note that the indices of a and $b$ are off by one from paper because matlab can't index an array w/zero.

$\%$ Parameters

$\%$ initial population size

N_pop $=100$;

$\%$ number of attempts at a nest

$\mathrm{K}=3$;

$\%$ prob of attempting nest (zero prior successes), vector of ones of length $\mathrm{K}$

$\mathrm{a}=\operatorname{ones}(\mathrm{K}, 1)$;

$\%$ prob of attempting another brood (second success), vector of ones of length $\mathrm{K}$

$\mathrm{b}=$ ones $(\mathrm{K}, 1)$;

if $\mathrm{J}<\mathrm{K}$

$\mathrm{b}(\mathrm{J}+1: \mathrm{K})=0$;

end

$\%$ total attempts, initialize vector of length $\mathrm{K}$ with zeros

$\mathrm{t}=\operatorname{zeros}(\mathrm{K}, 1)$;

$\%$ total successes, initialize vector of length $\mathrm{K}$ with zeros

$\mathrm{s}=\operatorname{zeros}(\mathrm{K}, 1)$;

$\%$ prepare indices of $\mathrm{b}$ with recursion

$\operatorname{alpha}(1,1)=0$;

for $\mathrm{i}=2: \mathrm{K}$

$\operatorname{alpha}\left(1: 2^{\wedge}(\mathrm{i}-2), \mathrm{i}\right)=\operatorname{alpha}\left(1: 2^{\wedge}(\mathrm{i}-2), \mathrm{i}-1\right)$;

$\operatorname{alpha}\left(2^{\wedge}(\mathrm{i}-2)+1: 2^{\wedge}(\mathrm{i}-1), \mathrm{i}\right)=\operatorname{alpha}\left(1: 2^{\wedge}(\mathrm{i}-2), \mathrm{i}-1\right)+1 ;$

end

$\%$ compute $\mathrm{T}$, see eqn 2 in manuscript

$\mathrm{T}(1,1)=\mathrm{a}(2) * \mathrm{~b}(1) * \mathrm{~N} \_$pop; 
$\mathrm{t}(1)=\mathrm{T}(1,1)$;

for $\mathrm{i}=2: \mathrm{K}$

for $\mathrm{m}=1: 2^{\wedge}(\mathrm{i}-1)$

$\% \mathrm{~m}$ is odd

if $\bmod (\mathrm{m}, 2)==1$

$\mathrm{T}(\mathrm{i}, \mathrm{m})=\mathrm{T}(\mathrm{i}-1, \operatorname{ceil}(\mathrm{m} / 2)) *(1-\mathrm{p}(\mathrm{i}-1)) * \mathrm{a}(\mathrm{i}) * \mathrm{~b}(\operatorname{alpha}(\mathrm{m}, \mathrm{i})+1) ;$

else

$\% \mathrm{~m}$ is even

$\mathrm{T}(\mathrm{i}, \mathrm{m})=\mathrm{T}(\mathrm{i}-1, \operatorname{ceil}(\mathrm{m} / 2))^{*} \mathrm{p}(\mathrm{i}-1) * \mathrm{a}(\mathrm{i}) * \mathrm{~b}(\operatorname{alpha}(\mathrm{m}, \mathrm{i})+1) ;$

end

end

$\mathrm{t}(\mathrm{i})=\operatorname{sum}(\mathrm{T}(\mathrm{i},:))$;

end

$\mathrm{s}=\mathrm{t} .{ }^{*} \mathrm{p}$

$\%$ nest success $=$ season long

$\mathrm{ns}=\operatorname{sum}(\mathrm{s}) / \operatorname{sum}(\mathrm{t}) ;$

$\%$ per capita birth rate $=\#$ female offspring $/$ adult female per season

br $=\operatorname{dot}(\mathrm{s}, \mathrm{y}) / \mathrm{N} \_$pop;

$\%$ total non-breeders

N_non $=$ N_pop* $(1-b(1))$

\section{REFERENCES}

[1] Thompson BC, Gregory E, Knadle B, et al. Nest success is not an adequate comparative estimate of avian reproduction. J Field Ornithol 2001; 72(4): 527-36.

[2] Mayfield HF. Suggestions for calculating nest success. Wilson Bull 1975; 87: 456- 66

[3] Mayfield HF. Nesting success calculated from exposure. Wilson Bull 1961; 73(3): 255- 61.

[4] Johnson DH. Estimating nest success: the Mayfield method and an alternative. Auk 1979; 96: 651- 61.

[5] Hensler GL, Nichols JD. The Mayfield method of estimating nesting success: A model, estimators, and simulation results. Wilson Bull 1981; 93: 42-53.

[6] Bart J, Robson DS. Estimating survivorship when the subjects are visited periodically. Ecology 1982; 63(4): 1078- 90.
[15] Skutch AF. Clutch size, nesting success and predation on nests of Neotropical birds, reviewed. Ornithol Monogr 1985; 36: 575- 94.

[16] Martin TE, Scott J, Menge C. Nest predation increases with parental activity: separating nest site and parental activity effects. R Soc Lond Proc Biol Sci 2000; 267: 2287-93.

[17] Flaspohler DJ, Temple SA, Rosenfield RN. Species-specific edge effects on nest success and breeding bird density in a forested landscape. Ecol Appl 2001; 11: 32-46.

[18] Farnsworth GL, Simons TR. How many baskets? Clutch sizes that maximize annual fecundity of multiple-brooded birds. Auk 2001; 118: $973-82$.

[19] Schmidt KA, Whelan CJ. The relative impacts of nest predation and brood parasitism on seasonal fecundity in songbirds. Conserv Biol 1999; 13: 46-57.

[20] Pease CM, Grzybowski JA. Assessing consequences of brood parasitism and nest predation on season fecundity in passerine birds. Auk 1995; 112: 343-63.

[21] Williams BK, Nichols JD, Conroy MJ. Analysis and management of animal populations 2002; Academic Press.

[22] Klett AT, Johnson DH. Variability in nest survival rates and implications to nesting studies. Auk 1982; 99(1): 77-81.

[23] Donovan TM, ThompsonIII FR, Faaborg J, Probst JR. Reproductive success of migratory birds in habitat sources and sinks. Conserv Biol 1995; 9: 1380-95.

[24] Lowther PE. Brown-headed cowbird. Birds North Am 1993; 47: 124.

[25] Aebischer A, Perrin N, Krieg M, Studer JM, Meyer D. The role of territory choice, mate choice and arrival date on breeding success in the Savi's warbler Locustella luscinioides. J Avian Biol 1996; 27(2): 143-52.

[26] Barba E, Gil-Delgado JA, Monros JS. The costs of being late: consequences of delaying great tit Parus major first clutches. J Anim Ecol 1995; 64: 642-51.

[27] Bryant DM. Reproductive costs in the house martin (Delichon urbica). J Anim Ecol 1979; 48(2): 655-75. 